
problems. A quasi-experimental study on the translator's acquisition of cultural competence", Across Languages and Cultures, Vol. 20 No. 2, pp. 253-273. https://doi.org/10.1556/084.2019.20.2.6

\title{
Applying internalised source-culture knowledge to solve cultural translation problems. A quasi-experimental study on the translator's acquisition of cultural competence
}

\author{
CHRISTIAN OLALLA-SOLER \\ Departament de Traducció i d'Interpretació i d'Estudis de l'Àsia Oriental \\ Universitat Autònoma de Barcelona \\ Edifi ci MRA Campus de la UAB · 08193 Bellaterra \\ (Cerdanyola del Vallès) $\cdot$ Barcelona $\cdot$ Spain \\ Phone: + 34935812761 \\ E-mail: christian.olalla@uab.cat
}

\begin{abstract}
In this article the ability to efficiently apply internalised source-culture knowledge when solving cultural translation problems is analysed at different stages of acquisition of the translator's cultural competence by means of a cross-sectional, quasi-experimental study. Thirty-eight BA students from the first through fourth year studying Translation and Interpreting at the Universitat Autònoma de Barcelona, as well as ten professional translators participated in this investigation. The subjects' knowledge of German culture and their knowledge of a selection of cultural translation problems in a text were measured prior to its translation. The translation strategies employed by the subjects to solve these problems were recorded and classified using PACTE's (2017b) sequences of actions. The quality of the subjects' solutions to the cultural translation problems of the text was assessed with PACTE's (2017a) acceptability index. These data were combined to compute the source-culture knowledge application index. Results show that the students in all cohorts preferred to utilise information-seeking strategies even when they possessed cultural knowledge about a specific cultural translation problem, while the professional translators in this study were able to apply their internalised source-culture knowledge. The solutions proposed by both the translation students and the professional translators were of a higher quality when internalised source-culture knowledge was applied.
\end{abstract}

Keywords: internalised source-culture knowledge, information-seeking strategies, acquisition of the translator's cultural competence, quasi-experimental study. 
This is a post-print version of the following published paper:

Olalla-Soler, Christian (2019). " Applying internalised source-culture knowledge to solve cultural translation problems. A quasi-experimental study on the translator's acquisition of cultural competence", Across Languages and Cultures, Vol. 20 No. 2, pp. 253-273. https://doi.org/10.1556/084.2019.20.2.6

\section{INTRODUCTION}

The aim of this paper is to present the partial results of a quasi-experimental study on the acquisition of the translator's cultural competence in the case of German-Spanish translation. Specifically, we present the results of one of the indicators of the study: the source-culture knowledge application index. It provides information on the subjects' ability to make use of their internalised source-culture knowledge efficiently with the goal of resolving cultural translation problems in a text depending on the subjects' level of cultural knowledge. This index provides information about one of the components proposed in Olalla-Soler's (2017a) model of the translator's cultural competence: culture-related contrastive skill. The research presented here was conducted by means of a process and product-oriented, cross-sectional, quasiexperiment with 38 BA students of Translation and Interpreting at the Universitat Autònoma de Barcelona (UAB), with German as a second foreign language and 10 professional translators.

When solving cultural translation problems, translators may use strategies based on their internalised cultural knowledge, that is, knowledge of the source and target cultures that the translator has acquired and stored cognitively (Olalla-Soler 2017a), as well as informationseeking strategies to gain cultural knowledge. Since resource consultation implies a higher cognitive load than translation drafting and revision (Tangsgaard Hvelplund 2017), translators may use their internalised cultural knowledge more frequently than information seeking strategies to be more efficient in their translation process when this knowledge is available and accessible. However, translation students may not have accumulated as much cultural knowledge as translators because they have less professional experience (Olalla-Soler 2017a) and their information-seeking skills may not be fully developed (Olalla-Soler 2018). These differences between students and professional translators regarding their internalised cultural knowledge and information-seeking skills have not yet been investigated.

This paper concentrates on the subjects' internalised source-culture knowledge and purports to respond to the following questions, which may be of interest for translator training: (1) Do the translation students and the professional translators in this study differ in the way they apply their internalised source-culture knowledge when solving cultural translation problems? (2) How does the application of internalised source-culture knowledge change as the acquisition of the translator's cultural competence advances in the case of the students in this study? (3) Are the strategies based on the application of internalised source-culture knowledge employed by the students in this study related to translation solutions of a higher quality than information-seeking strategies? 
This is a post-print version of the following published paper:

Olalla-Soler, Christian (2019). " Applying internalised source-culture knowledge to solve cultural translation problems. A quasi-experimental study on the translator's acquisition of cultural competence", Across Languages and Cultures, Vol. 20 No. 2, pp. 253-273. https://doi.org/10.1556/084.2019.20.2.6

This paper is structured as follows: the conceptual framework is discussed first. Second, the design of the quasi-experimental study is presented. Information about the hypotheses, the participants, the source-culture knowledge application index, the data-collection tools, the dataanalysis procedure, and the ethical issues that had to be addressed is offered. Third, the results of the index are reported. Fourth, the results are discussed and linked to other investigations. Finally, we present the most relevant conclusions and discuss the limitations of the study.

\section{THEORETICAL FRAMEWORK}

The ability to make use of knowledge of the source and target cultures, to relate to them, and apply this knowledge when translating is one of the key components of most translator's (inter)cultural competence models. With the exception of Taft's (1981) model, this ability is included in Witte's (2000) competence-between-cultures, in Bahumaid's (2010) specific translation skills, in PICT's (2012) textual dimension, in Yarosh's (2012) interculturallycompetent core translation behaviour and comparative cultural knowledge, and in OlallaSoler's (2017a) culture-related contrastive skill. All these models include a conceptual dimension related to the possession of cultural knowledge and a contrastive dimension oriented toward the ability to compare cultural knowledge to translate. From an empirical perspective, some studies on the translation of cultural references have found evidence of the division between possessing cultural knowledge and being able to contrast it (Olk 2009; Bahumaid 2010; Olalla-Soler 2017a).

Culture can be defined from several perspectives. Faulkner et al. (2006) compiled and classified 300 definitions of culture into several categories, one of them being structural definitions. Here, culture is conceived as a system of elements: ways of life, cognitive systems, individual and communal behavioural systems, language and discourse, relational systems, and social organisation. As cultural knowledge associated with these elements may be too extensive to possess it all, it seems unlikely that translators would rely exclusively on their internalised cultural knowledge to solve cultural translation problems. Thus, translators may make use of information resources to gain cultural knowledge and then apply it in solving problems. While the cognitive load is higher during resource consultation than during translation drafting and revision (Tangsgaard Hvelplund 2017), both strategies (applying one's internalised cultural knowledge and making use of information resources to gain cultural knowledge) are refined and applied more efficiently with the development of expertise (PACTE 2017b), understood as the 
This is a post-print version of the following published paper:

Olalla-Soler, Christian (2019). " Applying internalised source-culture knowledge to solve cultural translation problems. A quasi-experimental study on the translator's acquisition of cultural competence", Across Languages and Cultures, Vol. 20 No. 2, pp. 253-273. https://doi.org/10.1556/084.2019.20.2.6

property of a person who performs an operation or a set of operations in a limited domain with exceptional results when compared to others capable of performing the same operation (Ericsson and Smith 1991, cit. in Muñoz Martín 2009:25).

Translators may accumulate and store cultural knowledge in their long-term, declarative memory (Tulving 1983) by performing professional translation tasks (Olalla-Soler 2017a) and by deliberately learning about the working cultures (Yarosh 2012; Gutiérrez Bregón 2016). If the cultural translation problem is salient enough for the translator to identify it, if they have accumulated relevant cultural knowledge to interpret it and to translate it, and if this knowledge is accessible to them (Collins and Loftus 1975; Shepherd 2011), they may turn to their internalised cultural knowledge to solve this problem. If the translator does not possess (relevant) cultural knowledge or it is not accessible, they may turn to information-seeking strategies. Thus, it would be expected that, with higher levels of expertise and accumulated internalised cultural knowledge, translators would turn to this knowledge to solve cultural translation problems rather than to information-seeking strategies, which may hinder the efficiency of the translation process and could imply a high cognitive load.

While translation students may acquire cultural knowledge through deliberate practice in the classroom (Shreve 2006) and by actively engaging with their working cultures (Yarosh 2012; Gutiérrez Bregón 2016), their internalised cultural knowledge is lower than that of professional translators (Olalla-Soler 2017a) because of the possible difference in age and accumulated professional experience. Since translation competence acquisition and cultural competence acquisition are considered as actions in which the translation process becomes more efficient as their acquisition progresses (Olalla-Soler 2017a; PACTE forthcoming), differences should be observable as students internalise cultural knowledge and develop their information-seeking skills. This development would cause an efficient use of translation strategies resulting in better translation solutions as training advances.

By means of a cross-sectional quasi-experiment, we explored the differences between a group of translation students with German as a second foreign language studying in the Translation and Interpreting BA programme at UAB, along with a group of professional translators, regarding the efficiency of use of their internalised source-culture knowledge when solving cultural translation problems. Specifically, we concentrated on the subjects' internalised source-culture knowledge. 
This is a post-print version of the following published paper:

Olalla-Soler, Christian (2019). " Applying internalised source-culture knowledge to solve cultural translation problems. A quasi-experimental study on the translator's acquisition of cultural competence", Across Languages and Cultures, Vol. 20 No. 2, pp. 253-273. https://doi.org/10.1556/084.2019.20.2.6

\section{RESEARCH DESIGN}

The design of the quasi-experimental study was based on PACTE's (2014) translation competence acquisition experiment (TCA). Although acquisition processes should be investigated with longitudinal studies with single-sample measurements (Field and Hole 2003; Vignoles 2017), because they "better capture the developmental path of the learner" (Watorek and Perdue 2017: 180), it was decided to use a cross-sectional design due to the methodological limitations of longitudinal studies when long periods of time and many repeated measurements are involved. These limitations are: the excessive amount of time needed for data collection, the possible high subject-dropout rate, and the complexity of validating parallel data-collection instruments. While the results obtained do not strictly describe an acquisition process and their generalisation is not appropriate given the small sample size of the quasi-experiment (see 3.2. Participants), several factors that influence the process of acquiring cultural competence have been controlled (the subject's age, the courses taken during the BA, the completion of stays abroad and the subject's professional experience, among others). In this way, we attempted to control the students' pedagogical context to facilitate the comparison between groups and thus, be able to attribute the changes perceived to the effect of the acquisition of this competence.

\subsection{Research questions}

We formulated the following research questions:

1. Do the translation students and the professional translators in this study differ in the way they apply their internalised source-culture knowledge when solving cultural translation problems?

2. How does the application of internalised source-culture knowledge change as the acquisition of the translator's cultural competence advances in the case of the students in this study?

3. Are the strategies based on the application of internalised source-culture knowledge employed by the students in the study related to translation solutions of a higher quality than information-seeking strategies?

\subsection{Participants}

The population under study consisted of UAB translation students with German as a second foreign language and Spanish as their mother tongue. A sample of 
This is a post-print version of the following published paper:

Olalla-Soler, Christian (2019). " Applying internalised source-culture knowledge to solve cultural translation problems. A quasi-experimental study on the translator's acquisition of cultural competence", Across Languages and Cultures, Vol. 20 No. 2, pp. 253-273. https://doi.org/10.1556/084.2019.20.2.6

these students with German as a second foreign language and without experience as professional translators was selected from each of the four years of the BA in Translation and Interpreting at $\mathrm{UAB}$. The sample of students was comprised of 38 subjects (Table 1). The students' performance was compared to that of ten translators with the German-Spanish language pair who had a minimum of ten years' experience as professional translators. Translation was determined to be their principal professional activity as it provided at least $70 \%$ of their income. Unlike the student sample, the professional translators were did not receive any kind of training during the period when the quasi-experiment was undertaken.

Table 1. Main characteristics of the sample

\begin{tabular}{|c|c|c|c|c|c|c|c|}
\hline & $\mathrm{N}$ & $\begin{array}{l}\text { Age } \\
\text { (median) }\end{array}$ & $\begin{array}{l}\text { German (L3) } \\
\text { level } \\
\text { according to } \\
\text { CEFR }\end{array}$ & L1 & $\begin{array}{l}\text { Has he/she } \\
\text { failed any of } \\
\text { the previous } \\
\text { courses? }\end{array}$ & $\begin{array}{l}\text { Years of } \\
\text { experience as } \\
\text { professional } \\
\text { translator (mean) }\end{array}$ & $\begin{array}{l}\text { Is translation } \\
\text { his/her main } \\
\text { professional } \\
\text { activity? }\end{array}$ \\
\hline 1 st year & 12 & 18 & A1 & Spanish & No & No experience & - \\
\hline 2nd year & 8 & 19.5 & A2 & Spanish & No & No experience & - \\
\hline 3rd year & 9 & 20 & B1 & Spanish & No & No experience & - \\
\hline 4 th year & 9 & 22 & B2 & Spanish & No & No experience & - \\
\hline Translators & 10 & 36 & $\mathrm{C} 1-\mathrm{C} 2$ & Spanish & - & 16.4 & Yes \\
\hline
\end{tabular}

\subsubsection{Pedagogical context}

During the BA in Translation and Interpreting at UAB, socio-cultural contents in German as a second foreign language are addressed in the first three years (Olalla-Soler 2017a). The first and second years cover general aspects of German culture such as gastronomy, geography, history, customs and traditions, family relations, and behavioural issues. These contents are taught in language courses. During the third year, cultural aspects are dealt with in a translation course that includes solving cultural translation problems. The training in cultural aspects is rather general, and the application of source-culture knowledge to actual translations is only explicitly practised in one translation course. 
This is a post-print version of the following published paper:

Olalla-Soler, Christian (2019). " Applying internalised source-culture knowledge to solve cultural translation problems. A quasi-experimental study on the translator's acquisition of cultural competence", Across Languages and Cultures, Vol. 20 No. 2, pp. 253-273. https://doi.org/10.1556/084.2019.20.2.6

\subsection{Computing the Source-Culture Knowledge Application Index}

To compute this index, we combined the results obtained in the measurements of the following variables of the quasi-experiment:

- Index of knowledge of German culture: the subjects' declarative knowledge about German culture (Olalla-Soler 2017a).

- Index of cultural knowledge prior to translation of the cultural translation problems: the subjects' cultural knowledge about the cultural translation problems in the text prior to its translation (Olalla-Soler 2017a).

- Sequences of actions: chains of actions carried out by a subject to achieve the final solution in each of the cultural translation problems (Olalla-Soler 2019).

The source-culture knowledge application index is combined with acceptability, a measure of the translation quality, which was used to observe the relationship between the application of the subjects' internalised source-culture knowledge and the quality of the proposed solutions to the cultural translation problems. According to PACTE (2017a:119), a translation is acceptable when it "effectively communicates the meaning of the source text; fulfils the function of the translation (within the context of the translation brief, readers' expectations and genre conventions in the target culture); and makes appropriate use of language”. Following PACTE's methodology, acceptability was measured in five specific rich points (that is, prototypical cultural translation problems) of the text to be translated, which were validated by two expert judgments (see Section 3.4.1). For each rich point, a degree of acceptability was established (PACTE 2017a:120-121):

- Acceptable solution (numeric value: 1): the solution activates all the relevant connotations of the source text in the target text as regards the meaning of the source text, the function of the translation, and language use.

- Semi-acceptable solution (numeric value: 0.5 ): the solution activates some of the relevant connotations of the source text in the target text and maintains the coherence of the target text with regard to the meaning of the source text, the function of the translation, and language use.

- Non-acceptable solution (numeric value: 0 ): the solution activates none of the relevant connotations of the source text in the target text or introduces connotations that are incoherent with regard to the meaning of the source text, the function of the translation, and/or language use.

For more details on the assessment of acceptability, see Section 3.5.3. 
This is a post-print version of the following published paper:

Olalla-Soler, Christian (2019). " Applying internalised source-culture knowledge to solve cultural translation problems. A quasi-experimental study on the translator's acquisition of cultural competence", Across Languages and Cultures, Vol. 20 No. 2, pp. 253-273. https://doi.org/10.1556/084.2019.20.2.6

\subsection{Data Collection Tools}

The data-collection instruments are presented below.

\subsubsection{The text to be translated and the subjects' translations}

This instrument was used to gather data for the acceptability index. The text used was an article entitled "Lautstark gegen die Ostalgie", written by Hauke Friedrichs and published in 2009 in Die Zeit Online. It was preceded by a translation brief. The text deals with the victims of political measures in the German Democratic Republic (GDR), who protested against the use of GDR symbols for commercial and touristic purposes. It was shortened with the help of an expert in German text typology and, in 2010, underwent a first expert judgement by a panel of five professional translators and translator trainers at the $\mathrm{UAB}$ to validate a first selection of culturemes as rich points. These rich points covered all cultureme types described by Molina (2001), who defines a cultureme as "a verbal or para-verbal element that has a specific cultural load in a culture and that, when coming into contact with another culture through translation, can cause a cultural problem between the source and target texts" (2001: 89, own translation). In November 2013, it underwent a second judgement to ensure that the topic was still culturally accessible despite the elapsed time. After the second judgement, the following rich points were selected (Olalla-Soler 2017a):

- Ostalgie (linguistic culture): part of the article title and reference to the topic is based on a culturally marked neologism.

- Spreemetropole (natural environment): reference to Berlin by referring to the river that flows through the city.

- Grenzeruniformen (cultural patrimony): play of contrasts between the reference to the soldiers who guarded the Berlin Wall (negatively perceived by German citizens) and the parody for tourists performed by actors dressed up as Berlin Wall soldiers.

- Arbeiter- und Bauernstaat (social culture): reference to communism used as synonym for the former GDR.

- Unrechtstaat [...] DDR-Regime [...] SED-Diktatur (referential chain): characterisation of the former GDR government and the Socialist Unity Party of Germany by using synonyms with negative connotations.

The instrument can be found in Olalla-Soler (2017a). 
This is a post-print version of the following published paper:

Olalla-Soler, Christian (2019). " Applying internalised source-culture knowledge to solve cultural translation problems. A quasi-experimental study on the translator's acquisition of cultural competence", Across Languages and Cultures, Vol. 20 No. 2, pp. 253-273. https://doi.org/10.1556/084.2019.20.2.6

\subsubsection{Questionnaire of declarative knowledge of German culture}

This instrument was used to gather data for the index of knowledge of German culture. The questionnaire for declarative knowledge on German culture consists of 30 items that represent four cultural areas: organisation of the natural environment, organisation of the cultural patrimony, organisation of society, and models of behaviour, values, and ideas. It includes multiple-choice items with three to four options and a single correct answer. The design of the items was based on various information sources, such as the Einbürgerungstest, the Federal Republic of Germany's (RFA) naturalisation test, which foreigners must pass to be eligible for German citizenship, and the results of Schroll-Machl's study on central cultural standards of the RFA population (2002). The validation consisted of three phases and each of them focused on a specific aspect: content validity, criterion validity, and face validity. The validation process was carried out with the participation of teachers of German as a second foreign language from the BA in Translation and Interpreting at the UAB, students of German as a first and second foreign language of the same degree, and citizens of the RFA in various age groups. This instrument can be found in Olalla-Soler (2017a).

We only collected data related to the source culture. This decision was made because the personal background of each subject complicated the process of delimiting the cultural aspects of their own culture that should be known to them. We consider that the measurement of knowledge of one's own culture is beyond the scope of this study and would correspond to other topics of research.

\subsubsection{Template for the identification and characterisation of culturemes}

This instrument was used to gather data for the index of cultural knowledge prior to translation of the cultural translation problems. The template was divided into three tasks. In the first task, the subjects had to underline all the culturemes they encountered in the validated text by the two expert judgements. The second task was to categorise the culturemes that subjects had identified. The third task was to explain what some of the culturemes of the text meant. A table with seven culturemes was presented, four of which were the rich points. Three other culturemes that were not rich points were also included. These three culturemes were not used for the calculation of the index of cultural knowledge prior to translation of the culturemes and were included only to avoid the exclusive presentation of rich points, as this may have affected the translation process and the validity of the study. This instrument can be found in OlallaSoler (2017a). 
This is a post-print version of the following published paper:

Olalla-Soler, Christian (2019). " Applying internalised source-culture knowledge to solve cultural translation problems. A quasi-experimental study on the translator's acquisition of cultural competence", Across Languages and Cultures, Vol. 20 No. 2, pp. 253-273. https://doi.org/10.1556/084.2019.20.2.6

\subsubsection{Screen recordings}

This instrument was used to gather data for the sequences of actions. Process data was recorded using Camtasia@ (version 8), a screen recorder used in PACTE's TCA experiment (2014). With this software, data from strategies used in decision-making and the type of online information resources used by the subjects was gathered. The main reason why this software was chosen is related to ecological validity, as it does not interfere with the subject at any time during the quasi-experiment.

\subsection{Analysis}

In this section, we will present the analysis method for each indicator and how they were transformed to be employed for the calculation of the source-culture knowledge application index.

\subsubsection{Index of knowledge of German culture and index of cultural knowledge prior to translation of the cultural translation problems}

The answers to the 30 items of the questionnaire of declarative knowledge on German culture were awarded a 1 if the answer was correct and 0 if it was incorrect. To calculate the index of knowledge of German culture, the correct answers for each cultural area were added together and divided by the total number of items in the corresponding area (a mean for each area). Subsequently, the means for each area were added together and divided by the total number of areas (mean of the four areas). In this way, an index with a range of 0 (low knowledge) to 1 (high knowledge) was obtained.

To extract the data for the index of cultural knowledge prior to translation of the cultural translation problems, we used a task aimed at explaining a series of culturemes that appeared in the template for the identification and characterisation of such culturemes. We assessed whether the subjects had correctly explained the rich points. A 1 was awarded if it had been correctly explained, a 0.5 if it had been partially correctly explained, and a 0 if it had been incorrectly explained. To assess these three levels of correctness, we used criteria based on the responses of subjects who participated in the pilot test (Olalla-Soler 2017b). Once the data was recorded, the mean of the four rich points was calculated. An index with a range of 0 (low knowledge) to 1 (high knowledge) was obtained.

The mean of the two indices was computed for each subject to obtain a single indicator that included both the general source-culture knowledge possessed by 
This is a post-print version of the following published paper:

Olalla-Soler, Christian (2019). " Applying internalised source-culture knowledge to solve cultural translation problems. A quasi-experimental study on the translator's acquisition of cultural competence", Across Languages and Cultures, Vol. 20 No. 2, pp. 253-273. https://doi.org/10.1556/084.2019.20.2.6

the subjects and their specific knowledge of the rich points of the text to be translated. This mean represents the internalised source-culture knowledge that each subject possesses, varying between 0 (a null level of internalised source-culture knowledge) and 1 (the highest level). The next step was to classify the subjects' means into three categories according to the level of internalised source-culture knowledge: low level (means from 0 to 0.33 ), medium level (means from 0.34 to 0.66 ) and high level (means from 0.67 to 1 ). Table 2 shows the results of the two indices and the mean of both by group. See Olalla-Soler (2017a) for an in-depth analysis of these results.

Table 2. Index of knowledge of German culture, index of cultural knowledge prior to translation of the cultural translation problems, and level of internalised cultural knowledge by group: mean and standard deviation (in brackets)

\begin{tabular}{clll}
\hline & $\begin{array}{l}\text { Index of knowledge } \\
\text { of German culture }\end{array}$ & $\begin{array}{l}\text { Index of cultural knowledge prior to } \\
\text { translation of the cultural translation problems }\end{array}$ & $\begin{array}{l}\text { Level of cultural, } \\
\text { internalised knowledge }\end{array}$ \\
\hline $1^{\text {st }}$ year & 0.34 & 0.04 & 0.21 \\
& $(0.08)$ & $(0.06)$ & $(0.05)$ \\
$2^{\text {nd }}$ year & 0.45 & 0.25 & 0.35 \\
& $(0.07)$ & $(0.15)$ & $(0.09)$ \\
$3^{\text {rd }}$ year & 0.50 & 0.28 & 0.39 \\
& $(0.08)$ & $(0.15)$ & $(0.07)$ \\
$4^{\text {th }}$ year & 0.59 & 0.46 & 0.53 \\
& $(0.10)$ & $(0.28)$ & $(0.14)$ \\
Translators & 0.74 & 0.83 & 0.78 \\
& $(0.07)$ & $(0.20)$ & $(0.10)$ \\
\hline
\end{tabular}

\subsubsection{Sequences of actions}

When translating problematic culturemes, the subjects may use strategies relating to either internal resources (declarative knowledge possessed by the subjects and retrieved to identify and interpret a cultural translation problem, as well as to translate it into the target text in a functionally adequate way) or to external resources (declarative knowledge not possessed by the subjects and acquired through consultation of information resources at the moment of solving a cultural translation problem). The strategies that can be employed cannot be arranged along a discrete binary scale, but along a continuum that ranges from the exclusive use of internal resources to the use of external resources alone. PACTE (2009: 222-223) categorises these strategies into four sequences of actions that 
This is a post-print version of the following published paper:

Olalla-Soler, Christian (2019). " Applying internalised source-culture knowledge to solve cultural translation problems. A quasi-experimental study on the translator's acquisition of cultural competence", Across Languages and Cultures, Vol. 20 No. 2, pp. 253-273. https://doi.org/10.1556/084.2019.20.2.6

subjects carry out to reach a solution to a translation problem, regardless of type. These sequences of actions have been ordered from greater to lesser use of internalised source-culture knowledge:

- Internal support (IS): no queries prior to the final solution are necessary. Only the subject's internalised source-culture knowledge is applied.

- Predominantly internal support (PIS): this implies combinations of queries that do not include bilingual consultations with a copy of the solution offered. The subject's internalised source-culture knowledge is used, and information is obtained from information resources that do not provide an equivalent to the problem in the target language/culture.

- Predominantly external support (PES): this implies combinations of queries that include bilingual consultations containing the solution offered. Both internalised source-culture knowledge and information resources of all kinds are used: queries are performed in sources that provide an equivalent to the problem in the target language and in other sources, such as encyclopaedias or monolingual dictionaries.

- External support (ES): this implies only bilingual consultations containing the equivalent offered. No internalised source-culture knowledge is applied, and the solution is reached through the exclusive selection of an equivalent provided by a bilingual dictionary.

The percentage of use of each sequence type per group is presented in Table 3. See OlallaSoler (2019) for a more detailed analysis of this indicator.

Table 3. Percentage of the use of each sequence of actions by group

\begin{tabular}{lllll}
\hline & Internal support & $\begin{array}{l}\text { Predominantly } \\
\text { internal support }\end{array}$ & $\begin{array}{l}\text { Predominantly } \\
\text { external support }\end{array}$ & External support \\
\hline $1^{\text {st }}$ year & 25.97 & 3.90 & 32.47 & 37.66 \\
$2^{\text {nd }}$ year & 23.21 & 1.79 & 32.14 & 42.86 \\
$3^{\text {rd }}$ year & 28.57 & 3.17 & 44.44 & 23.81 \\
$4^{\text {th }}$ year & 21.43 & 1.79 & 41.07 & 35.71 \\
Translators & 57.14 & 14.29 & 17.14 & 11.43 \\
\hline
\end{tabular}

To calculate the source-culture knowledge application index, we assigned a numerical value to each sequence according to the level of internalised source-culture knowledge applied. Internal support was coded as 1 , predominantly internal support as 0.5 , predominantly external support as -0.5 , and external support as -1 . The next step was to calculate the median of the seven rich points (the first four rich points plus the three sequences of actions of each part of the referential chain) 
This is a post-print version of the following published paper:

Olalla-Soler, Christian (2019). " Applying internalised source-culture knowledge to solve cultural translation problems. A quasi-experimental study on the translator's acquisition of cultural competence", Across Languages and Cultures, Vol. 20 No. 2, pp. 253-273. https://doi.org/10.1556/084.2019.20.2.6

per subject. The value obtained corresponds to the type of cultural resources used, with 1 being a complete application of internalised source-culture knowledge and -1 a complete application of external cultural resources. Table 4 presents the median obtained by each group. The median was used because it was a more robust central trend statistic than the mean - as long as the values of the index range on a scale with a mean value of zero.

Table 4. Type of applied cultural resources: median and standard deviation (in brackets)

\begin{tabular}{ll}
\hline & Type of applied cultural resources \\
\hline $1^{\text {st }}$ year & -0.21 \\
& $(0.18)$ \\
$2^{\text {nd }}$ year & -0.32 \\
& $(0.30)$ \\
$3^{\text {rd }}$ year & -0.07 \\
& $(0.24)$ \\
$4^{\text {th }}$ year & -0.25 \\
& $(0.20)$ \\
Translators & 0.46 \\
& $(0.44)$ \\
\hline
\end{tabular}

\subsubsection{Calculating the source-culture knowledge application index}

Once the means of the internalised source-culture knowledge of each subject had been calculated, the median of the type of applied resources for each group and for each level of internalised source-culture knowledge was computed to obtain the source-culture knowledge application index. This index ranged from -1 (use of external cultural resources) to 1 (use of internalised source-culture knowledge). As shown above, the median was used as it was a more robust central trend statistic than the mean.

A source-culture knowledge application index of 0.5 in the category of high level of internalised source-culture knowledge would indicate that those subjects who possess a high level of internalised source-culture knowledge tend to apply it to solve cultural translation problems. By contrast, a source-culture knowledge application index of -0.5 in the category of high level of internalised source-culture knowledge would mean that, despite the fact that subjects have a high level of internalised source-culture knowledge, they do not apply it often to solve cultural translation problems; instead, they tend to use information resources and the equivalents offered by bilingual dictionaries. 
This is a post-print version of the following published paper:

Olalla-Soler, Christian (2019). " Applying internalised source-culture knowledge to solve cultural translation problems. A quasi-experimental study on the translator's acquisition of cultural competence", Across Languages and Cultures, Vol. 20 No. 2, pp. 253-273. https://doi.org/10.1556/084.2019.20.2.6

\subsubsection{Relating the source-culture knowledge application index with acceptability}

To assess the efficiency of the subjects' application of their internalised source-culture knowledge, we first computed the acceptability mean of the five rich points for each subject and for each group. We then calculated the acceptability mean by group. For the assessment of the solutions, criteria were established based on the solutions proposed by the subjects who participated in the pilot test of the quasi-experiment (Olalla-Soler 2017b). To reduce the possible bias that may exist if the assessment was undertaken by only one evaluator, two evaluators participated in the assessment process. Both were BA teachers of Translation and Interpretation at the UAB, as well as professional translators. One was a native German speaker and the other was a native Spanish speaker. The evaluation was done jointly. The results obtained in the acceptability index are presented in Table 5. See Olalla-Soler (2019) for a deeper analysis of these results.

Table 5. Acceptability by group: mean and standard deviation (in brackets)

\begin{tabular}{ll}
\hline & Acceptability \\
\hline $1^{\text {st }}$ year & 0.22 \\
& $(0.14)$ \\
$2^{\text {nd }}$ year & 0.26 \\
& $(0.09)$ \\
$3^{\text {rd }}$ year & 0.34 \\
& $(0.16)$ \\
$4^{\text {th }}$ year & 0.43 \\
& $(0.18)$ \\
Translators & 0.61 \\
& $(0.14)$ \\
\hline
\end{tabular}

To measure the relationship between the index and acceptability, we divided the rich points of each subject and each group according to the subject's level of internalised sourceculture knowledge and according to the type of support used to solve each rich point: external support (ES), predominantly external and internal support (PES and PIS), and internal support (IS). For each subset, the acceptability mean of the rich points of each group was calculated.

\subsection{Statistical Analysis}

To determine if there were any differences between groups, the normality of the data was checked by creating $Q-Q$ plots and running Shapiro-Wilk normality tests 
This is a post-print version of the following published paper:

Olalla-Soler, Christian (2019). " Applying internalised source-culture knowledge to solve cultural translation problems. A quasi-experimental study on the translator's acquisition of cultural competence", Across Languages and Cultures, Vol. 20 No. 2, pp. 253-273. https://doi.org/10.1556/084.2019.20.2.6

for each group and each indicator. The data were not normally distributed in any group and in any indicator, thus, non-parametric tests were used. A Johnckheere-Terpstra test was run to observe if there was any increasing tendency on the part of the students to apply their internalised source-culture knowledge as training advanced. A Mann-Whitney $U$ test was applied to determine if there were any differences between the fourth-year students and the professional translators. Effect sizes are reported for all tests. The relationship between acceptability and the source-culture knowledge application index was analysed descriptively given the low amount of cases in each subset.

\subsection{Ethical Issues}

We prepared a confidentiality and data-protection agreement according to the Spanish organic law $15 / 1999$ for data protection. Subjects signed this document if they agreed to the following terms:

- The translation process would be recorded.

- The gathered data would be treated confidentially, and subjects would not be individually identified in future publications.

- The data would not be given to third parties without the subjects' prior consent.

- The data gathered would have no effect on the subjects' academic records.

- The subjects had the right to obtain a copy of the results.

\section{RESULTS AND DISCUSSION}

From the first to the fourth year, the source-culture knowledge application index was always negative, indicating a general tendency to use external cultural resources to solve cultural translation problems regardless of the level of internalised source-culture knowledge (Table 6).

Among the first-year students, given the low level of internalised source-culture knowledge (Table 2), there was a tendency to use strategies based on external cultural resources. In the second and third year, the strategies used were also based on external cultural resources even in the case of those subjects who possessed a medium level of internalised source-culture knowledge (second year: $U=7.0, p=0.886$, two-tailed, $r=0.13$; third year: $U=5.5, p=0.381$, two-tailed, $r=0.39$ ). While using strategies based on external cultural resources at a low level of internalised source-culture knowledge may be due to a lack of prior knowledge, in the case of the medium level, it may rather be due to a prefer- 
This is a post-print version of the following published paper:

Olalla-Soler, Christian (2019). " Applying internalised source-culture knowledge to solve cultural translation problems. A quasi-experimental study on the translator's acquisition of cultural competence", Across Languages and Cultures, Vol. 20 No. 2, pp. 253-273. https://doi.org/10.1556/084.2019.20.2.6

Table 6. Source-culture knowledge application index by level of internalised source-culture knowledge and by group: mean and standard deviation (in brackets)

\begin{tabular}{llll}
\hline & $\begin{array}{l}\text { Low level of internalised } \\
\text { source-culture knowledge } \\
(0-0.33)\end{array}$ & $\begin{array}{l}\text { Medium level of internalised } \\
\text { source-culture knowledge } \\
(0.34-0.66)\end{array}$ & $\begin{array}{l}\text { High level of internalised } \\
\text { source-culture knowledge } \\
(0.67-1)\end{array}$ \\
\hline $1^{\text {st }}$ year & -0.21 & - & - \\
& $(0.18)$ & -0.36 & - \\
$2^{\text {nd }}$ year & -0.29 & $(0.19)$ & - \\
& $(0.41)$ & -0.22 & -0.21 \\
$3^{\text {rd }}$ year & -0.07 & $(0.26)$ & $(0.00)$ \\
& $(0.15)$ & -0.29 & 0.57 \\
$4^{\text {th }}$ year & - & $(0.21)$ & $(0.47)$ \\
& & 0.36 & \\
Translators & - & $(0.00)$ & \\
\hline
\end{tabular}

ence for using strategies based on external resources, which is still present in the fourth-year group (Table 2). ${ }^{1}$ The group of professional translators is the one that possessed the highest level of internalised source-culture knowledge and the one that applied it most when solving cultural translation problems.

All the years had a very different performance from that of the translators. This is particularly relevant in the case of the fourth year, since it indicates that training did not seem to change the students' preference for strategies based on external cultural resources. In addition, there was no evidence of changes from the first to fourth year, as the values obtained were very similar between pairs of consecutive years (low level of internalised source-culture knowledge: $T_{J T}=60.5 ; z=1.422 ; p=0.155, r=0.34$; medium level: $T_{J T}=54.5 ; z=-0.081 ; p$ $=0.935, r=0.02$; high level: $T_{J T}=8 ; z=1.222 ; p=0.222, r=0.39$ ).

The students in the study tended to favour the use of information-seeking strategies that provide equivalents in the target language, possibly because they did not trust their internalised source-culture knowledge and considered it safer to look for the necessary knowledge in external resources. However, the use of external resources may imply a greater cognitive load. Tangsgaard Hvelplund (2017) found that the cognitive load is greater when consulting information resources than when drafting a translation. This is particularly the case when information is not rapidly retrievable, and queries are carried out and redefined until a solution is found (Enríquez Raído 2011). We also observed this in the results of the variable use of instrumental resources for the acquisition of cultural knowledge (Olalla-Soler 2018): the students of all years had many consultations, used inadequate resources for their information needs (Varantola 1998; Massey and Ehrensberger- 
This is a post-print version of the following published paper:

Olalla-Soler, Christian (2019). " Applying internalised source-culture knowledge to solve cultural translation problems. A quasi-experimental study on the translator's acquisition of cultural competence", Across Languages and Cultures, Vol. 20 No. 2, pp. 253-273. https://doi.org/10.1556/084.2019.20.2.6

Dow 2011) and invested a lot of time in queries. The cognitive load assigned to control the processes of identifying an information need, of searching for information, of formulating the query, of evaluating the information found, and, if it is not profitable, of formulating another query until necessary information is obtained, can be much higher than solving cultural translation problems with one's own internalised source-culture knowledge, if such knowledge exists and is accessible.

\subsection{Acceptability and Source-Culture Knowledge Application Index}

In the third and fourth years, acceptability rose as internalised source-culture knowledge increased, and the use of this knowledge to solve cultural translation problems also rose (Table 7). Among the first-year students, strategies based on external cultural resources obtained a higher degree of acceptability than those based on both internal and external resources. The first-year students possessed little source-culture knowledge, and they needed to acquire it through strategies based on external cultural resources. In the second year, there seemed to be no clear trend regarding accept-

Table 7. Acceptability mean of the source-culture knowledge application index by level of internalised source-culture knowledge and by group

\begin{tabular}{|c|c|c|c|c|}
\hline & $\begin{array}{l}\text { Type } \\
\text { resources used }\end{array}$ & $\begin{array}{l}\text { Low level of } \\
\text { internalised source- } \\
\text { culture knowledge } \\
(0-0.33)\end{array}$ & $\begin{array}{l}\text { Medium level of } \\
\text { internalised source- } \\
\text { culture knowledge } \\
(0.34-0.66)\end{array}$ & $\begin{array}{l}\text { High level of } \\
\text { internalised } \\
\text { source-culture } \\
\text { knowledge } \\
(0.67-1)\end{array}$ \\
\hline \multirow[t]{3}{*}{$1^{\text {st }}$ year } & External & 0.28 & - & - \\
\hline & External and internal & 0.17 & - & - \\
\hline & Internal & - & - & - \\
\hline \multirow[t]{3}{*}{$2^{\text {nd }}$ year } & External & 0.10 & 0.33 & - \\
\hline & External and internal & 0.27 & 0.20 & - \\
\hline & Internal & - & - & - \\
\hline \multirow[t]{3}{*}{$3^{\text {rd }}$ year } & External & - & 0.33 & - \\
\hline & External and internal & 0.20 & 0.50 & - \\
\hline & Internal & - & - & - \\
\hline \multirow[t]{3}{*}{$4^{\text {th }}$ year } & External & - & 0.44 & - \\
\hline & External and internal & - & 0.47 & 0.50 \\
\hline & Internal & - & - & - \\
\hline \multirow[t]{3}{*}{ Translators } & External & - & - & 0.50 \\
\hline & External and internal & - & - & 0.70 \\
\hline & Internal & - & 0.60 & 0.80 \\
\hline
\end{tabular}


This is a post-print version of the following published paper:

Olalla-Soler, Christian (2019). " Applying internalised source-culture knowledge to solve cultural translation problems. A quasi-experimental study on the translator's acquisition of cultural competence", Across Languages and Cultures, Vol. 20 No. 2, pp. 253-273. https://doi.org/10.1556/084.2019.20.2.6

ability. In the third and fourth years, acceptability was higher when the level of internalised source-culture knowledge was higher and when it was applied. Yet, strategies based on external cultural resources were the most widely used. In the translators' group, the tendency presented in the third and fourth years was even more obvious: the higher the level of internalised sourceculture knowledge and the more it was applied, the greater the degree of acceptability obtained.

\section{CONCLUSIONS}

The following conclusions could be drawn with regard to our initial research questions:

1. As training advances, the students in this study tended to use external cultural resources when solving cultural translation problems regardless of the level of internalised sourceculture knowledge.

2. Only the professional translators applied their internalised source-culture knowledge when solving cultural translation problems.

3. The way the students in this study applied their internalised source-culture knowledge when solving cultural translation problems was opposite to that of the translators.

4. In the case of the third-year and fourth-year students and the professional translators, the quality of the proposed solutions to cultural translation problems was higher when their internalised source-culture knowledge was applied to solve these problems.

The translator's fully developed cultural competence appears to be characterised by an efficient application of internalised source-culture knowledge when solving cultural translation problems. While this was clearly observable in the case of the translators in this study, it was not so in the student sample. We consider that this may be due to the pedagogical context in which the students have acquired cultural competence, since the application of source-culture knowledge to actual translations was only practised in one translation course included in the Translation and Interpretation BA programme. We believe that the translators' accumulated professional experience may have also played a crucial role in their different approach to solving cultural problems.

As mentioned in the results and discussion section, another possible explanation for the students' low application of internalised source-culture knowledge when solving cultural translation problems may be their lack of confidence, together with their excessive reliance on information resources (Hirci 2013). However, in- 
This is a post-print version of the following published paper:

Olalla-Soler, Christian (2019). " Applying internalised source-culture knowledge to solve cultural translation problems. A quasi-experimental study on the translator's acquisition of cultural competence", Across Languages and Cultures, Vol. 20 No. 2, pp. 253-273. https://doi.org/10.1556/084.2019.20.2.6

formation-seeking processes are sometimes unavoidable, and in fact, they can be desirable in many occasions. For example, information resources can be used not only to acquire previously inexistent cultural knowledge, but also to confirm existing knowledge and expand it. These preliminary information-seeking processes may help translators to increase efficiency and quality by confirming that their already existing knowledge is applicable when solving a specific cultural translation problem. While the results obtained in this study might not be generalisable to the whole population of translation students, it may be helpful for them (or at least for students in the UAB Translation and Interpretation BA programme) that translation courses explicitly worked on ways to solve information needs arisen from cultural translation problems by making use of information resources to conduct both preliminary queries and also queries to obtain new, relevant cultural knowledge.

We believe that translation students need to be aware of their information-seeking process, to identify the information needs arising from cultural translation problems, to be familiar with and select the most appropriate resources for their information needs, to plan what they will look for and how they will search for it in the selected resources, and to critically evaluate the information resources and the outcome of their queries. By performing these tasks they will be able to critically assess whether they need external resources to solve a given cultural translation problem or whether their internalised source-culture knowledge is sufficient, accessible, and trustworthy.

\section{Limitations of the Study}

The quasi-experimental study presented in this paper has certain limitations, as it has been conducted with a small sample size and just one language pair. Consequently, the experiment should be replicated with larger samples, more language pairs, more texts, and more rich points, as well as in various pedagogical contexts. It should include a control group formed of bilingual subjects who are not professional translators. In this way, it would be possible to: 1) obtain more accurate data, 2) compare the results obtained with those of other language combinations, and 3) clearly establish the differences between the characteristic behaviour of professional translators and the one shared with bilingual speakers with regard to cultural competence. Due to time constraints in conducting this study, it was only possible to design and validate a questionnaire on knowledge of the source culture. To provide a more comprehensive view of the subjects' cultural knowledge and the way they apply both their internalised source and target-culture knowledge, it would be necessary to design and validate other data-collection instruments related to the subjects' own culture. 
This is a post-print version of the following published paper:

Olalla-Soler, Christian (2019). " Applying internalised source-culture knowledge to solve cultural translation problems. A quasi-experimental study on the translator's acquisition of cultural competence", Across Languages and Cultures, Vol. 20 No. 2, pp. 253-273. https://doi.org/10.1556/084.2019.20.2.6

\section{NOTES}

${ }^{1}$ No significance test was performed for the fourth year and the group of translators since one of the two categories only contained data from one case.

\section{REFERENCES}

Bahumaid, S. 2010. Investigating cultural competence in English-Arabic translator training programs. Meta: Journal des Traducteurs Vol. 55. No. 3. 569-588.

Collins, A. M. \& Loftus, E. F. 1975. A spreading-activation theory of semantic processing. Psychological Review Vol. 82. No. 6. 407-428.

Enríquez Raído, V. 2011. Investigating the web search behaviors of translation students: An exploratory and multiple-case study.PhD dissertation, Universitat Ramon Llull, Spain.

Ericsson, K. A. \& Smith, J. (eds.). 1991. Toward a General Theory of Expertise: Prospects and Limits. New York: Cambridge Press.

Faulkner, S. L.; Baldwin, J. R.; Lindsley, S. L. \& Hecht, M. L. 2006. "Layers of meaning: an analysis of definitions of culture". In: Baldwin, J. R.; Faulkner, S. L.; Hecht, M. L. \& Lindsley, S. L. (eds.) Redefining Culture. Perspectives Across the Disciplines. Mahwah: Lawrence Erlbaum. 27-52.

Field, A. \& Hole, G. 2003. How to Design and Report Experiments. London/ Thousand Oaks/ New Delhi: SAGE Publications Ltd.

Gutiérrez Bregón, S. 2016. La competencia intercultural en la profesión del traductor: aproximación desde la formación de traductores y presentación de un estudio de caso. Trans. Revista de Traductología No. 20. 57-74.

Hirci, N. 2013. Changing trends in the use of translation resources: The case of trainee translators in Slovenia. ELOPE: English Language Overseas Perspectives and Enquiries Vol. 10. No. 2. 149-165.

Massey, G. \& Ehrensberger-Dow, M. 2011. Investigating information literacy: A growing priority in Translation Studies. Across Languages and Cultures Vol. 12. No. 2. 193-211.

Molina, L. 2001. Análisis descriptivo de la traducción de los culturemas árabe-español. PhD dissertation, Universitat Autònoma de Barcelona, Spain.

Muñoz Martín, R. 2009. Expertise and environment in tranlsation. Mutatis Mutandis Vol. 2. No. 1. 24-37.

Olalla-Soler, C. 2017a. La competencia cultural del traductor y su adquisición. Un estudio experimental en la traducción alemán-español. $\mathrm{PhD}$ dissertation, Universitat Autònoma de Barcelona, Spain.

Olalla-Soler, C. 2017b. Un estudio experimental sobre la adquisición de la competencia cultural en la formación de traductores. Resultados del estudio piloto. Meta Vol. 62. No. 2. 435460.

Olalla-Soler, C. 2018. Using electronic information resources to solve cultural translation problems. Journal of Documentation Vol. 74 No. 6. 1293-1317.

Olalla-Soler, C. 2019. Using translation strategies to solve cultural translation problems. Differences between students and professional translators. Perspectives Vol. 27 No. 3. 367-388.

Olk, H. M. 2009. Translation, cultural knowledge, and intercultural competence. Journal of Intercultural Communication No. 20. 7-7.

PACTE. 2009. Results of the validation of the PACTE translation competence model: Acceptability and decision making. Across Languages and Cultures Vol. 10. No. 2. 207230. 

problems. A quasi-experimental study on the translator's acquisition of cultural competence", Across Languages and Cultures, Vol. 20 No. 2, pp. 253-273. https://doi.org/10.1556/084.2019.20.2.6

PACTE. 2014. First results of PACTE group's experimental research on translation competence acquisition: The acquisition of declarative knowledge of translation. MonTI: Monografías de Traducción eInterpretación Special issue 1. 85-115.

PACTE. 2017a. Acceptability. In: Hurtado Albir, A. (ed.) Researching Translation Competence by PACTE Group. Amsterdam: John Benjamins. 119-130.

PACTE. 2017b. Decision-making. In: Hurtado Albir, A. (ed.) Researching Translation Competence by PACTE Group. Amsterdam: John Benjamins. 191-210.

PACTE. Forthcoming. Evolution of the efficacy of the translation process in translation competence acquisition. Results of the PACTE group's experimental research. Meta Vol. 64. No 1.

PICT. 2012. Intercultural Competence. Curriculum Framework. http://www.pictllp.eu/download/curriculum/PICT-CURRICULUM_ENGLISH.pdf (17.12.2017).

Schroll-Machl, S. 2002. Die Deutschen - Wir Deutsche. Fremdwahrnehmung und Selbstsicht im Berufsleben. Göttingen: Vandenhoeck \& Ruprecht.

Shepherd, H. 2011. The cultural context of cognition: What the implicit association test tells us about how culture works. Sociological Forum Vol. 26. No. 1. 121-143.

Shreve, G. M. 2006. The deliberate practice: Translation and expertise. Journal of Translation Studies Vol. 9. No. 1. 27-42.

Taft, R. 1981. "The role and personality of the mediator". In: Bochner, S. (ed.) The Mediating Person: Bridges between Cultures. Massachusetts: Schenkman Publishing Company. 5388

Tangsgaard Hvelplund, K. 2016. Cognitive efficiency in translation. In: Muñoz Martín, R. (ed.) Reembedding Translation Process Research. Amsterdam: John Benjamins. 149-170.

Tangsgaard Hvelplund, K. 2017. Translators' use of digital resources during translation. Hermes No. 56. 71-87.

Tulving, E. 1983. Elements of Episodic Memory. New York: Oxford University Press.

Varantola, K. 1998. "Translators and their use of dictionaries: User needs and user habits." In: Atkins, B. T. S. (ed.) Using Dictionaries. Studies of Dictionary Use by Language Learners and Translators. Tübingen: Niemeyer. 179-192.

Vignoles, A. 2017. "Longitudinal research". In: Coe, R; Waring, M.; Hedges, L. V. \& Arthur, J. (eds) Research Methods \& Methodologies in Education. Los Angeles: SAGE. 130-137.

Watorek, M. \& Perdue, C. 2017. "Cross-sectional and longitudinal analyses.” In: Byram, M. \& Hu, Adelheid (eds.) Routledge Encyclopedia of Language Teaching and Learning. Oxon: United Kingdom. 180.

Witte, H. 2000. Die Kulturkompetenz des Translators. Tübingen: Stauffenberg Verlag.

Yarosh, M. 2012. Translator intercultural competence: The concept and means to measure the competence development. PhD dissertation, University of Deusto, Spain. 